Research Article

\section{Production and evaluation of enzyme- modified lighvan cheese using different levels of commercial enzymes}

\author{
Mohammad B Habibi Najafi ${ }^{1 *}$ and Mohammad Amin Miri² \\ ${ }^{1}$ Food Science \& Technology Department, Agriculture Faculty, Ferdowsi University of Mashhad, \\ Mashhad, Iran \\ ${ }^{2}$ Food Science \& Technology Department, Agriculture Faculty, University of Zabol, Zabol, Iran
}

\section{Abstract}

Enzyme-modified cheeses are concentrated cheese flavors produced enzymatically from dairy substrates in order to provide an intense source of cheese flavor with broad applications. Lighvan cheese is an Iranian traditional cheese with a pleasant taste and flavor generated after ripening. Therefore, the objective of the present study was to use commercial enzymes to produce enzyme-modified Lighvan cheese made from unripened and immature cheese. In this study, Neutrase $(0.05 \%, 0.15 \%$, and $0.2 \%)$ and Flavourzyme $(0.05 \%, 0.1 \%$, and $0.2 \%)$ were added to the base mixture. The resulting mixture was stored in an incubator for 24,72 , and $96 \mathrm{~h}$ to provide intense cheese flavor. Sensory evaluations of all samples in terms of bitterness, flavor, taste, and general acceptance were also carried out.

The results of the sensory evaluations revealed no significant difference between most of the samples in terms of bitterness, flavor, taste, and general acceptance with respect to the incubation duration and the type and level of the commercial enzymes $(p \leq 0.05)$. However, the effect of the different concentrations of Flavourzyme on the cheese texture was significant after 24,72 , and $96 \mathrm{~h}$ of incubation $(p \leq 0.05)$. In addition, the effects of the different concentrations of Neutrase on the cheese texture were significant after $96 \mathrm{~h}$ of incubation $(p \leq 0.05)$. Finally, the effect of different concentrations of Flavourzyme on the general acceptance of the samples was significant following 24,72 , and $96 \mathrm{~h}$ of incubation $(p \leq 0.05)$. In general, considering the flavor, taste, texture and general acceptance scores of the enzyme-modified Lighvan cheese samples, the best sample was the sample produced by using $0.1 \%$ Neutrase and $0.1 \%$ Flavourzyme mixture.

\section{More Information}

*Address for Correspondence: Mohammad B Habibi Najafi, Food Science \& Technology Department, Agriculture Faculty, Ferdowsi University of Mashhad, Mashhad, Iran, Tel: +98 9153139466; Email: habibi@um.ac.ir; mohhabibi@gmail.com

Submitted: 18 February 2020

Approved: 26 February 2020

Published: 27 February 2020

How to cite this article: Najafi MBH, Miri MA. Production and evaluation of enzyme-modified lighvan cheese using different levels of commercial enzymes. Int J Clin Microbiol Biochem Technol. 2020; 3: 011-016.

DOI: 10.29328/journal.ijcmbt.1001009

ORCiD: orcid.org/0000-0002-0498-1067

Copyright: (C) 2020 Najafi MBH, et al. This is an open access article distributed under the Creative Commons Attribution License, which permits unrestricted use, distribution, and reproduction in any medium, provided the original work is properly cited.

Keywords: Lighvan cheese; Enzyme-modified cheese; Commercial enzymes; Sensory properties

Check for updates

OPEN ACCESS

\section{Introduction}

There is an increasing demand in the world to produce dairy-based or non-dairy products with specific cheese flavor. Therefore, any technology associated with the quick production of concentrated cheese flavor and taste, can considerably reduce the expenses and the prices. The application of exogenous enzymes to immature or semiripened cheese, produce cost effective intense flavor of that cheese which is known as Enzyme Modified Cheese (EMC) and is suitable to be incorporated in many formulation and in a variety of foods such as bakery, confectionery, processed cheese, cheese sauce as partial or whole replacement of natural cheese. Moreover, EMCs are also used to reduce fat content or to replace fat functionality in low-fat products due to health-related concerns of saturated fat and cholesterol in traditional dairy products [1].

The EMC technology is based on the incorporation of certain enzymes in order to produce the final flavor and taste of cheese from a suitable substrate within 72 to $96 \mathrm{~h}$ under optimum conditions. These enzymes are a mixture of proteases, peptidases, lipases, and esterases. Currently, a wide range of these enzymes is commercially available with microbial and animal sources and is used in the production of different varieties of enzyme-modified cheese $[2,3]$.

Flavourzyme is produced from Aspergillus oryzae strains and is used for hydrolysis of protein under neutral or slightly acid conditions. It is an aminopeptidase, mixture of peptidase, endopeptidase and exopeptidase. It is possible to carry out over $70 \%$ of hydrolysis of peptide linkage. Flavourzyme hydrolyzed products created from being mixed with bitter peptidase are diverse, mostly small peptides and amino acids. The optimal temperature for active Flavourzyme is about 50$55{ }^{\circ} \mathrm{C}, \mathrm{pH}$ about $5-7$. Flavourzyme is inactivated at $85{ }^{\circ} \mathrm{C}$ for 5-10 minutes or at $120^{\circ} \mathrm{C}$ for 5 seconds [4]. 
Neutrase is an endopeptidase derived from Bacillus amyloliquefaciens that randomly hydrolyses internal peptide bonds. It is used in hydrolysis of plant and animal protein due to their high enzyme activity, good thermal stability, natural health security and other characteristics. Neutrase is extensively used in food, medicine, feed, cosmetic, leather and textile industries [5]. It has an optimum activity around pH 5.5-7.5 and $40-55^{\circ} \mathrm{C}$. Neutrase is inactivated at $85{ }^{\circ} \mathrm{C}$ for 2 minutes.

Cheddar EMC is probably the most widely used cheese flavor ingredient and is available as a range of products, differing in purported sensory properties [6]. Habibi-Najafi, et al. produced Cheddar EMC without bitterness using Neutrase $0.5 \mathrm{~L}$ and crude enzyme extract from Lactobacillus casei ssp. casei LLG. EMC supplemented with Neutrase ${ }^{\circledR} 0.5 \mathrm{~L}$ tended to induce accumulation of intense bitter peptide. This accumulation could be reduced by further treatment of the slurries with peptidases particularly proline specific peptidases [7]. The incubation of bitter EMC with cell free extract from Lactobacillus casei ssp. casei LLG resulted in the debittering of EMC within a few hours [7]. Ali, et al. produced EMC using soy milk-cow's milk. The soy milk-cow's milk curd was hydrolyzed by combination of proteinases/ peptidases and followed by lipolysis to create flavored EMC. They reported that enzymes led to an increase in amino acids, free fatty acids, complex volatiles, and improved sensory attributes. EMCs were less bitter, pungent, more buttery, saltier, nutty, and had sweet sensory characteristics [8]. Azarnia, et al. investigated the effect of natural crude enzyme or recombinant aminopeptidase, both derived from Lactobacillus rhamnosus S93, in the presence of a commercial proteinase (Neutrase) on the proteolysis of enzyme-modified Cheddar cheese. They reported that the EMC containing the recombinant aminopeptidase alone resulted in the complete disappearance of proline after $1 \mathrm{~d}$ of maturation time [9]. Mousavi-Nasab, et al. produced EMC by Aspergillus oryzae and Aspergillus niger. The EMC produced using both A. oryzae and A. niger had the best score of flavor and odor after 3 days of storage [10]. Ali, et al. produced enzyme modified white cheese (EMWC) to be used as flavoring ingredient. White cheese was hydrolyzed using mixture of proteinases and peptidases to produce a range of proteolyzed products followed by lipolysis. Enzyme modified white cheese was spray dried and its physical properties including solubility, thermal stability and morphology of powder was also studied [11].

Lighvan cheese is one of the most popular Iranian traditional raw milk cheeses, which mainly produced in Azerbaijan region, the north-west of Iran, usually from raw ewe's milk [12]. Since Lighvan cheese, is the most favorable Iranian cheese in terms of taste and flavor, it was decided to produce an enzyme-modified Lighvan cheese (Lighvan EMC) and to study the effects of two commercial enzymes (Flavourzyme a peptidase and Neutrase a protease) on the sensory attributes of final product. To the best of our knowledge, this paper is the first to study the production and some features of Lighvan EMC.

\section{Materials and methods}

\section{Materials}

Premature Lighvan cheese was purchased from Lighvan village, East Azerbaijan Province of Iran. Neutrase $0.8 \mathrm{~L}$ (P1236), and Flavourzyme 500 L (P6110) were supplied from the Novo Nordisk Company (Denmark).

\section{Production of Enzyme-Modified Cheese (EMC)}

The EMC was produced using the method proposed by Park, et al. [13]. Briefly, grated Lighvan cheese (600 g) was mixed with $2.5 \%$ sodium phosphate $\left(\mathrm{Na}_{2} \mathrm{Hpo}_{4}\right)$ and was heated at $90{ }^{\circ} \mathrm{C}$ for 3 minutes. Afterwards, the temperature of the mix was reduced to $50{ }^{\circ} \mathrm{C}$, and a mixture of Neutrase 0.8 $\mathrm{L}$ and Flavourzyme $500 \mathrm{~L}$ were added to the mix based on the treatment (Table 1). Each treatment was separately packed in plastic containers and then incubated for 24, 72, and $96 \mathrm{~h}$ at the optimum temperature of enzyme $\left(50{ }^{\circ} \mathrm{C}\right)$ provided by the manufacturer. At the end of incubation time, the slurry was heated to $80{ }^{\circ} \mathrm{C}$ to inactivate the enzyme and was then stored at $-20{ }^{\circ} \mathrm{C}$ until the day of experiments.

\section{Sensory evaluation}

Sensory evaluation was carried out using the five-point hedonic scale (ranked from extremely bad or 1 to extremely good or 5) [14]. To carry out a sensory analysis of the EMC samples, all treatments were assessed by 5 trained judges. Samples were dispensed in containers with the same color, size, and shape to ensure the uniformity of the conditions. Codes were then randomly assigned to each sample's container before performing the taste panel. After short explanation and training, the trained panel members were asked to evaluate the EMC in terms of bitterness, flavor, taste, texture, and general acceptance and write their opinions on the evaluation forms.

\section{Statistical analysis}

The data were statistically analyzed using a completely

Table 1: Actual values of dependent variables for each treatment.

\begin{tabular}{|c|c|}
\hline Flavourzyme Enzyme (\%) & Neutrase Enzyme (\%) \\
\hline 0.05 & 0 \\
\hline 0.05 & 0.05 \\
\hline 0.05 & 0.1 \\
\hline 0.05 & 0.15 \\
\hline 0.1 & 0 \\
\hline 0.1 & 0.05 \\
\hline 0.1 & 0.1 \\
\hline 0.1 & 0.15 \\
\hline 0.2 & 0 \\
\hline 0.2 & 0.05 \\
\hline 0.2 & 0.1 \\
\hline 0.2 & 0.15 \\
\hline
\end{tabular}


randomized design (CRD) with factorial structure with three replications. Analysis of variance (ANOVA) for all data was performed with MSTAT-C statistical software, version 2.10. Mean comparison was performed with LSD's test at the $p \leq$ 0.05 level of significance.

\section{Results and discussion}

\section{Bitterness}

Bitterness is one of the extremely common disadvantages of EMC products, and the EMC with the minimum bitterness is considered the best EMC [7]. The results revealed that the effect of enzymes on bitterness was not significant within the 24,72 , and 96 h of incubation $(p \leq 0.05)$. Figure $1(A-a)$ to (Ac) indicated that with an increase in the incubation time of Flavourzyme, bitterness increased and the scores showed a descending trend. Therefore, the highest score was obtained by the sample containing $0.05 \%$ Flavourzyme during $24 \mathrm{~h}$ of incubation, and the lowest score was obtained by the sample containing $0.1 \%$ Flavourzyme during $96 \mathrm{~h}$ of incubation. Furthermore, as the Flavourzyme level increased from $0.05 \%$ to $0.1 \%$ bitterness escalated, but the score obtained at the $0.2 \%$ level was higher than that of the $0.1 \%$ level despite the increase in the enzyme level.

According to figure 1 (B-a) to (B-c), with an increase in the incubation time of Neutrase, bitterness rises and the scores follow a descending trend. Therefore, the highest score was obtained by the samples incubated for $24 \mathrm{~h}$, and the lowest score was obtained by the samples incubated for $96 \mathrm{~h}$. In the samples incubated for $24 \mathrm{~h}$, the bitterness score decreased with an increase in the Neutrase level. Therefore, the lowest score was obtained by the sample containing $0.15 \%$ Neutrase. In the samples incubated for $72 \mathrm{~h}$, the highest score was obtained by the $0 \%$ Neutrase sample, but as the Neutrase level increased from $0.05 \%$ to $0.15 \%$, the bitterness score indicated an increasing trend. As a result, the differences between the scores of the $0.15 \%$ Neutrase sample and the $0 \%$ Neutrase sample was insignificant. In addition, of the samples incubated for $96 \mathrm{~h}$, the scores of the $0 \%$ and $0.15 \%$ Neutrase samples were lower than the other samples.

As seen, with an increase in the incubation time of the Neutrase treatments, bitterness increased. Habibi-Najafi and Lee reported that Neutrase tends to induce accumulation of intense bitter peptides. They observed that by the longer incubation time, the more fragments produced. They stated that one fraction of $\alpha_{s 1}$-casein including 6 amino acids (AlaPro-Phe-Pro-Glu-Val) and one fraction of $\beta$-casein including 3 amino acids (Phe-Leu-Leu) were responsible for creating bitterness flavor in EMC [7]. Bitterness also increased with the elongation of the incubation time of the Flavourzyme treatments, which could be attributed to the proteolytic activity of this enzyme. This proteolytic activity contributes to the separation of the hydrophobic bitter peptides from casein [15]. Ali, et al. stated that Flavourzyme and Neutrase significantly contributed to the bitterness were responsible for high levels of carboxy and amino-peptidases activities. They produced EMC by combination of Flavourzyme and PeptidaseR (which was derived from Rhizopus oryzae). This peptidase was applied to reduce significantly bitterness created by applying Flavourzyme and induced glutaminase activity to generate the natural flavor enhancer glutamic acid [8].

\section{Flavor and taste}

The research results indicated no significant difference between the samples in terms of flavor during the 24, 72, and $96 \mathrm{~h}$ of incubation $(p \leq 0.05)$. Figure $2(\mathrm{~A}-\mathrm{a})$ to (A-c) suggests that the sample with $0.1 \%$ Flavourzyme had the highest, lowest, and highest flavor scores at the 24, 72, and 96 $\mathrm{h}$ incubation periods, respectively. The results were reversed for the $0.05 \%$. Flavourzyme sample. On the contrary, the $0.2 \%$ Flavourzyme sample followed a growing trend during the 24, 72 , and $96 \mathrm{~h}$ of incubation. Figure 2 (B-a) to (B-c) illustrates the effect of the Neutrase enzyme on the sample flavor.

According to table, the samples did not differ significantly in terms of taste $(p \leq 0.05)$ (Figure 3 (A-a to B-c)). As mentioned, with an increase in the incubation time, the flavor score of the $0.2 \%$ Flavourzyme sample escalated. Flavourzyme is an enzyme with peptidolytic and proteolytic activities, and as its proteolytic activity increases, bitter hydrophobic peptides are produced from casein. Consequently, these bitter peptides
(A)

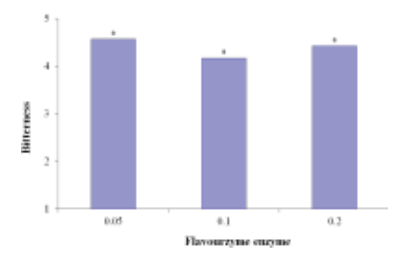

(a)

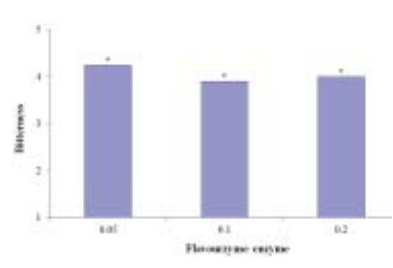

(b)

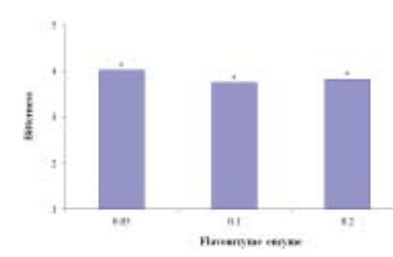

(c)
(B)

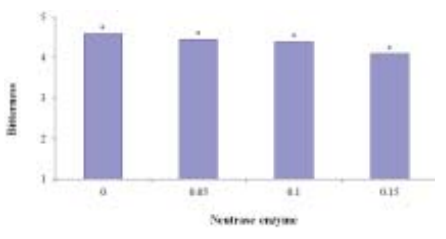

(a)

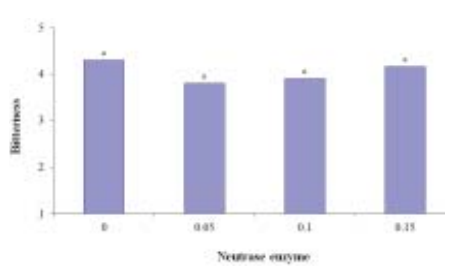

(b)

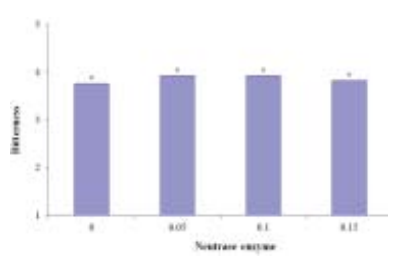

(c) 
(A)

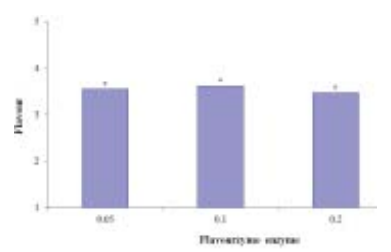

(a)

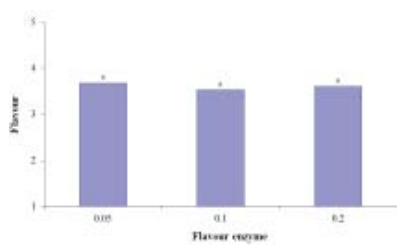

(b)

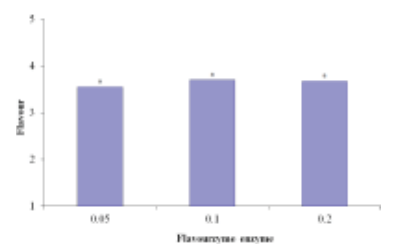

(c)
(B)

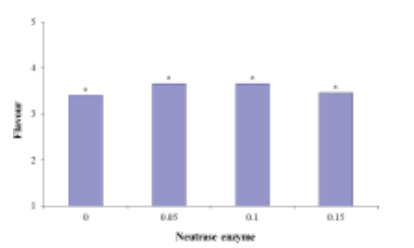

(a)

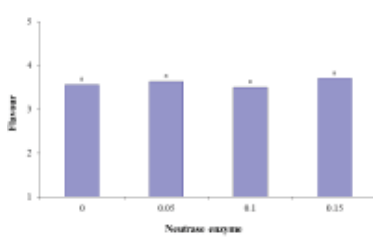

(b)

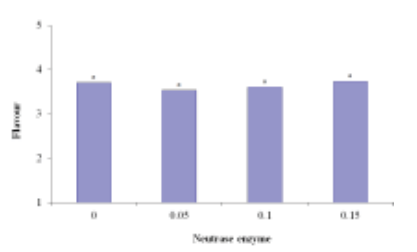

(c)

Figure 2: Effect of (A) Flavourzyme and (B) Neutrase enzymes on Flavor of Lighvan EMC at different hours: (a) 24, (b) 72, and (c) 96.

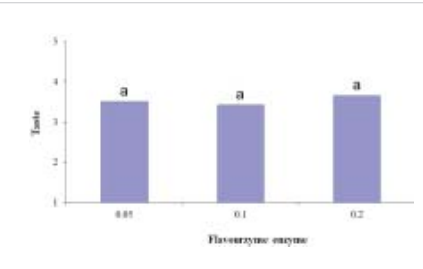

(a)

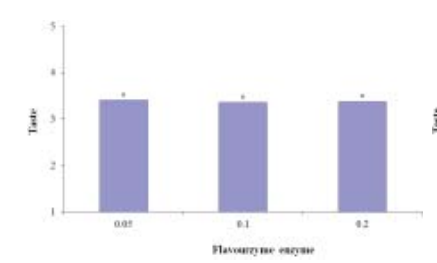

(b)

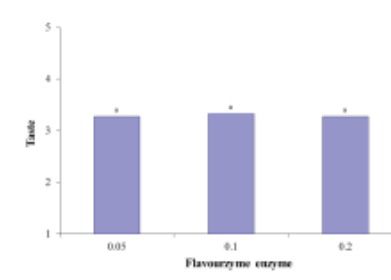

(c)

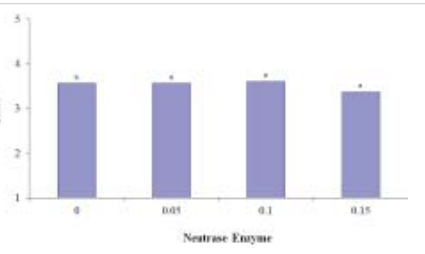

(a)

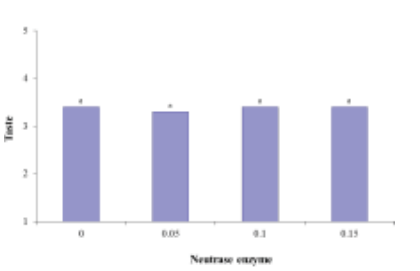

(b)

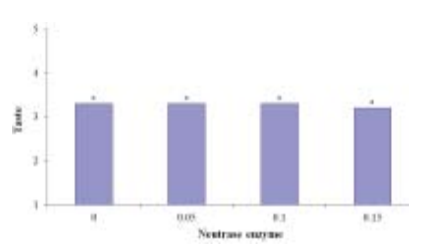

(c)
Figure 3: Effect of (A) Flavourzyme and (B) Neutrase enzymes on taste of Lighvan EMC at different hours: (a) 24, (b) 72, and (c) 96.

lose their peptidolytic activity and produce a pleasant taste and flavor. By comparing the samples treated during each incubation period it is possible to find a logical relationship between bitterness and taste, which can be attributed to the enzymatic activity. Salty taste appeared to be important intrinsic characteristic taste of the Lighvan substrate cheese. So, one of the factors that may contribute to the enhancement of flavor and taste is the high salt content of the initial substrate [8]. Enzyme modified white cheese produced using proteinases in combination with peptidases [11]. Lowered levels of bitterness, creamy and sensory attributes were reported in studied EMCs. Aspergillus oryzae and Aspergillus niger were used in production of EMC [10]. A. oryzae and $A$. niger, two kinds of molds, had proteolytic activity of $143 \mathrm{U} / \mathrm{g}$ and $38 \mathrm{U} / \mathrm{g}$, respectively. The EMC produced using both $A$. oryzae and A. niger had the best score of flavor and odor after 3 days of storage [10].

\section{Texture}

The effects of the Flavourzyme and Neutrase enzymes and the mutual effect of these enzymes on the texture of the samples were significant $(p \leq 0.05)$. However, time had no significant effect on texture. As the level of Flavourzyme changed from $0.05 \%$ to $0.1 \%$, the texture score escalated significantly $(p \leq 0.05)$, but the texture score decreased significantly when the level of this enzyme was changed from $0.1 \%$ to $0.2 \%(p \leq 0.05)$. The $0.05 \%$ and $0.2 \%$ samples did not differ significantly in terms of texture. The $0.1 \%$ Flavourzyme sample had the highest texture score (Figure 4 (A-a to A-c)). The $96 \mathrm{~h}$ of incubation significantly affected the texture of the Neutrase-containing samples, and the texture score escalated with an increase in the enzyme level during all of the incubation periods (Figure 4 (B-a to B-c)). The highest and lowest Neutrase texture scores were obtained by the samples
(A)

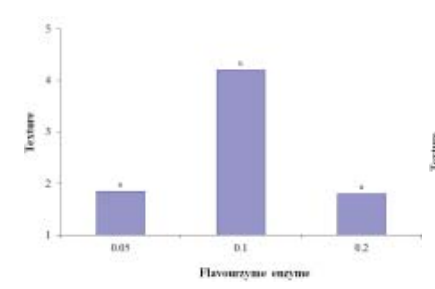

(a)

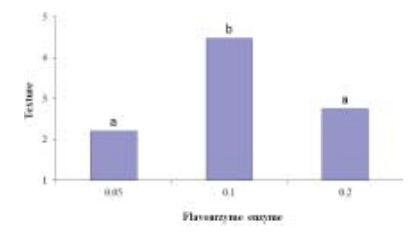

(b)

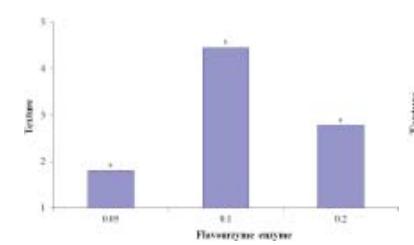

(c)
(B)

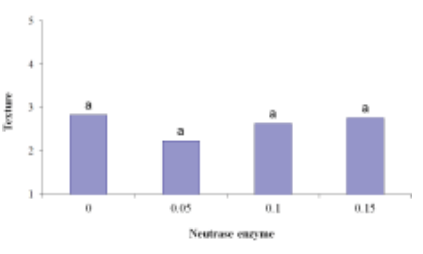

(a)

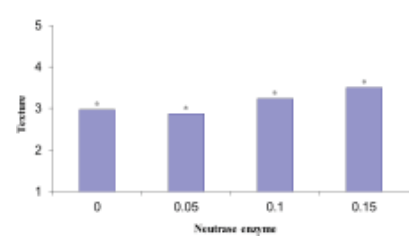

(b)

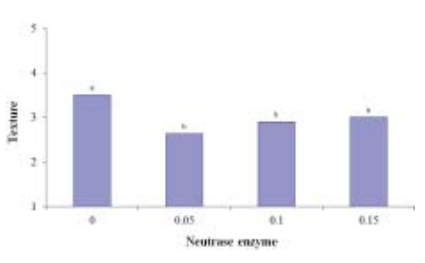

(c)
Figure 4: Effect of (A) Flavourzyme and (B) Neutrase enzymes on texture of Lighvan EMC at different hours: (a) 24, (b) 72 , and (c) 96. 
incubated for 72 and $24 \mathrm{~h}$. In fact, as the incubation time of the Neutrase samples increased from 24 to $72 \mathrm{~h}$, the texture score increased, while when the incubation time was changed from $72 \mathrm{~h}$ to $96 \mathrm{~h}$, the texture score declined. In general, the best sample was the $0.1 \%$ Flavourzyme texture-wise.

The satisfactory texture was observed in the pasty EMC, which was obtained using the $0.1 \%$ Flavourzyme and $0 \%$ Neutrase mix. The texture of the other samples was either granular or watery, which could be attributed to the enzyme type and the enzyme level. However, an unsatisfactory texture may also result from a lack of uniform distribution of the enzyme in the substrate [15]. The pasty texture is considered a disadvantage of ripe cheese and it is together with bitterness [2]. This is partly caused by the excess activity of the enzymes. By comparing the bitterness and textures of the test samples it was realized that the sample with the best texture had the lowest bitterness score. Hence, the satisfactory texture and excessive bitterness of the $0.1 \%$ sample could be attributed to the activity of the Flavourzyme enzyme. As stated, considering the Neutrase treatments, the Neutrase samples incubated for $24 \mathrm{~h}$ had the lowest score, which could be ascribed to the lack of an opportunity for enzymatic activity. In fact, the samples incubated for $24 \mathrm{~h}$ almost had the texture of the initial mixture.

\section{General acceptance}

The Flavourzyme enzyme had a significant effect on the general acceptance $(p \leq 0.05)$, whereas Neutrase did not have a significant effect on the general acceptance of the samples. As regards this attribute the incubation time did not have a significant effect on the general acceptance of the samples ( $p$ $\leq 0.05$ ). In general, as the level of Flavourzyme changed from 0.05 to $0.1 \%$, the general acceptance increased during all of the incubation periods. However, as the enzyme level reached $0.2 \%$, general acceptance declined significantly ( $p \leq 0.05)$. The general acceptance of the $0.05 \%$ and $0.1 \%$ samples decreased slightly with an increase in the incubation time. In terms of general acceptance, the best Flavourzyme sample was the $0.1 \%$ treatment (Figure 5 (A-a to A-c)). Generally, among the Neutrase treatments, the highest score was obtained by the $0.1 \%$ Neutrase sample during the $24 \mathrm{~h}$ incubation period. Although the general acceptance decreased slightly as the incubation time increased from 24 to $72 \mathrm{~h}$, an insignificant growth was observed during the $96 \mathrm{~h}$ incubation period. The behavior of the $0.15 \%$ Neutrase treatment was the opposite of the $0.1 \%$ treatment. In other words, as the incubation duration increased from $24 \mathrm{~h}$ to $72 \mathrm{~h}$, general acceptance expanded, but with an increase in the incubation time from 72 $\mathrm{h}$ to $96 \mathrm{~h}$ a slight decrease was spotted (Figure 5 (B-a to B-c)). Interestingly, the samples did not differ significantly from the $0 \%$ Neutrase sample, and even some of the samples had higher scores. Concerning their mutual effects, the general acceptance score of the $0.1 \%$ Flavourzyme treatment was the highest on all of the levels of the Neutrase enzyme during the $24 \mathrm{~h}$ incubation period and the lowest general acceptance
(A)

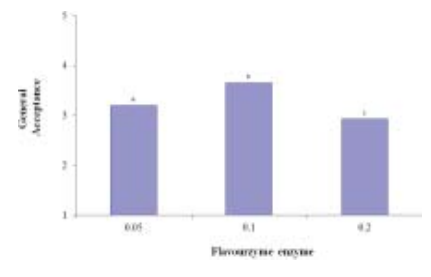

(a)

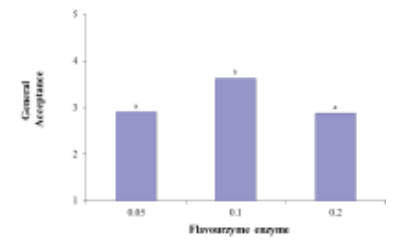

(b)

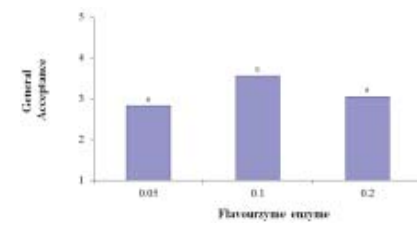

(c)
(B)

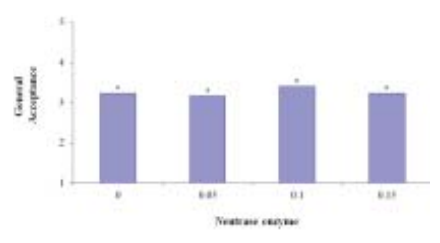

(a)

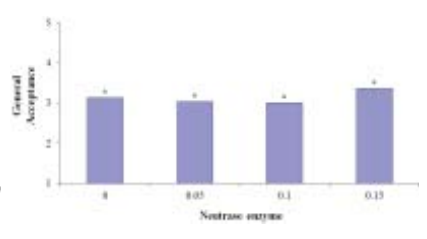

(b)

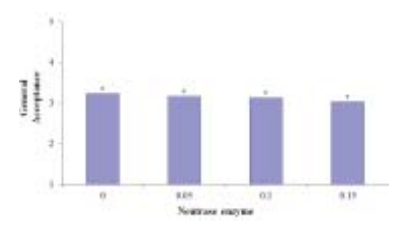

(c)

Figure 5: Effect of (A) Flavourzyme and (B) Neutrase enzymes on general acceptance of Lighvan EMC at different hours: (a) 24, (b) 72, and (c) 96.

score was obtained by the $0.2 \%$ Flavourzyme treatment at the $0 \%, 0.05 \%$, and $0.15 \%$ Neutrase levels. During the $72 \mathrm{~h}$ incubation period, the highest general acceptance score was obtained by the $0.1 \%$ Flavourzyme treatment on all of the levels of the Neutrase enzyme. Moreover, during the same period, the $0.15 \%$ Neutrase level yielded the highest general acceptance score. During the $96 \mathrm{~h}$ incubation period, the highest general acceptance score was obtained by the $0.1 \%$ Flavourzyme treatment on all levels of the Neutrase enzyme and the $0.2 \%$ treatment finished with the lowest score on the $0.05 \%, 0.1 \%$, and $0.15 \%$ levels.

Since general acceptance reflects the panel's opinion of the study samples and since the qualities of the given samples (such as texture, flavor, and taste) influence the general acceptance, the comparison drawn between the scores of the sensory properties revealed that the sample with the $0.1 \%$ Flavourzyme and $0.1 \%$ Neutrase mixture was the best sample during the 72 -h incubation period.

\section{Conclusion}

According to the above discussion on the Neutrase and Flavourzyme commercial enzymes, it seems that the level of these enzymes and the incubation period do not significantly affect bitterness due to the high salt content of the initial substrate. The results of the sensory evaluations indicated that the Flavourzyme enzyme significantly affected texture and general acceptance during the 24,72 , and $96 \mathrm{~h}$ incubation periods. Moreover, the Neutrase enzyme had a significant 
effect on texture during the $96 \mathrm{~h}$ incubation period. There was, however, no significant difference between the samples in terms of other sensory properties. In general, the sample with the $0.1 \%$ Flavourzyme and $0.1 \%$ Neutrase mixture can be considered the best sample of the Lighvan enzyme-modified cheese (Lighvan EMC) after 72 h of incubation.

\section{Acknowledgement}

I hereby declare that this piece of work was partially or fully funded by Ferdowsi University of Mashhad- Research affairs- with grant number: 17402 .

\section{References}

1. Miri MA, Najafi MBH. The effect of adding enzyme-modified cheese on sensory and texture properties of low- and high-fat cream cheeses. Int J Dairy Technol. 2011; 64: 92-98.

2. Fox PF. Cheese: chemistry, physics and microbiology. Chapman and Hall Publishing. 2004.

3. Kilcawley KN, Wilkinson MG, Fox PF. A survey of the composition and proteolytic indices of commercial enzyme-modified Cheddar cheese. Int Dairy J. 2000; 10: 181-190.

4. Hoa NT, Houang TTX, Minh NP, Dao DT. Investigation of enzymatic optimization by Flavourzyme and Celluclast for soy protein hydrolysate powder. Int J Adv Pharm Biol Chem. 2014; 3: 550-562.

5. Chen Z, Wang $Y$, Wei $L$, Wang J, Chen $\mathrm{H}$. Anovel cross-linked enzyme aggregates (CLEAs) of papain and neutrase-production, partial characterization and application. Int J Biol Macromol. 2017; 95: 650-657. PubMed: https://www.ncbi.nlm.nih.gov/pubmed/27913224

6. Miri MA. Enzyme Modified Cheese (EMC) in the formulation of cream cheese: study on sensory and texture properties. Ferdowsi university of Mashhad. 2010.

7. Habibi Najafi MB, Lee BH. Debittering of tryptic digests from beta casein and enzyme modified cheese by X-PDP. Iran J Sci Technol Trans a Sci. 2007; 31: 263-270.

8. Ali B, Khan KY, Majeed H, Xu L, Wu F, et al. Imitation of soymilk-cow's milk mixed enzyme modified cheese: their composition, proteolysis, lipolysis and sensory properties. J Food Sci Technol. 2017; 54: 1273-1285. PubMed: https://www.ncbi.nlm.nih.gov/pubmed/28416878

9. Azarnia S, Lee BH, Yaylayan V, Kilcawley KN. Proteolysis development in enzyme-modified Cheddar cheese using natural and recombinant enzymes of Lactobacillus rhamnosus S93. Food Chem. 2010; 120: 174-178.

10. Mousavi-Nasab M, Radi M, Afshari Jouybari H. Investigation of enzyme modified cheese production by two species of Aspergillus. Afr $\mathrm{J}$ Biotechnol. 2010; 9: 508-511.

11. Ali B, Khan KY, Majeed H, Xu L, Bakry AM, et al. Production of ingredient type flavoured white enzyme modified cheese. J Food Sci Technol. 2019; 56: 1683-1695.

PubMed: https://www.ncbi.nlm.nih.gov/pubmed/30996404

12. Aminifar M, Hamedi M, Emam-Djomeh Z, Mehdinia A. The effect of ovine and bovine milk on the textural properties of lighvan cheese during ripening. Int J Dairy Technol. 2013; 66: 45-53.

13. Park SY, Gibbs BF, Lee BH. Effects of crude enzyme of Lactobucillus casei LLG on water-soluble peptides of enzyme-modified cheese. Food Res Int. 1995; 28: 43-49.

14. Ghazizadeh M, Raseghi A. Basic Sensory methods for food evalvation. National nutrition and food technology research institute. 1998.

15. Haileselassie SS, Lee BH, Gibbs BF. Production of enzyme modified cheese and bioactive peptides by Lactobacillus and commercial enzymes. McGill University. 1999; 31-51. 